\title{
O ALONGAMENTO COMO FATOR INTERVINIENTE NA HIPERTROFIA MUSCULAR: UM ESTUDO PRELIMINAR
}

Gustavo dos Santos Ribeiro

\section{Resumo}

Muitas atribuições são dadas ao alongamento, contudo nem todas possuem comprovação científica. $\mathrm{O}$ objetivo deste estudo foi analisar os efeitos do alongamento durante o treinamento de força visando à hipertrofia muscular. A amostra do estudo foi composta por um individuo que treinou durante 16 semanas exercícios de força para M.S. e M.I. de modo unilateral, alongando os membros sinistros antes e após a sessão de treino. O resultado obtido foi um aumento na circunferência nos membros não-alongados e uma diminuição da espessura da prega cutânea no M.I. alongado, o M.S. alongado não apresentou diferença significativa com o não-alongado. Contudo mais estudos devem ser feitos para verificar os verdadeiros efeitos do alongamento no treinamento de força visando à hipertrofia.

\section{Palavras-Chave}

Fisiologia; Flexibilidade; Treinamento de Força.

\section{THE STRETCHING AS INTERVINIENTE FACTOR IN MUSCLE HYPERTROPHY: A PRELIMINARY STUDY}

Gustavo dos Santos Ribeiro

\begin{abstract}
A lot of attributions are given to the prolongation, however nor all possess scientific proof. The objective of this study was to analyze the effects of the prolongation during the training of force seeking to the muscular hypertrophy. The sample of the study was composed by an individual that for 16 weeks exercises of force for M.S. and M.I. in an unilateral way, prolongateing the sinister members before and after the training session.

The obtained result was an increase in the circumference in the no-prolonged members and a decrease of the thickness of the cutaneous pleat in M.I. prolonged, M.S. prolonged it didn't present significant difference with the no-prolonged. However more studies should be made to verify the true effects of the prolongation in the training of force seeking to the hypertrophy.
\end{abstract}

\section{Key-Words}

Physiology; Flexibility; Strength training. 


\section{Introdução}

Atualmente existem poucas pesquisas envolvendo a questão do alongamento com outras valências físicas (SIMÃO, et al. 2003). O que se vê é que muitas vezes é que o alongamento acaba sendo negligenciado por muitos praticantes de atividade física por falta de uma explicação convincente dada pelos profissionais que o ministram sobre os benefícios que este produz, contribuindo assim involuntariamente para uma valorização dos mitos que cercam a questão do alongamento.

Segundo Alter (1999) o alongamento nada mais é que um meio para se treinar a flexibilidade. Este tipo de treinamento produz alguns beneficios como à prevenção de lesões, o relaxamento muscular, o suprimento de sangue e nutrientes, a melhora da postura, entre outros (ALTER, 1999; BROOKS, 2000). Porém a maioria dos benefícios citados acima não possui comprovação científica.

Alguns trabalhos foram desenvolvidos nesta área com o intuito de conhecer mais sobre os efeitos fisiológicos que este tipo de treino produz. Haussinger (1990) e Millward (1995), por exemplo, verificaram em seus respectivos estudos que o alongamento aumentava o espaço físico das células, causando deste modo um maior espaço intracelular para a reserva de nutrientes. Brooks (2000) e Alter (1999) acreditam que este aumento na reserva irá proporcionar uma maior oferta de nutrientes para a produção de energia durante a contração e a recuperação muscular, contribuindo assim para a otimização do treinamento, tornando o exercício mas eficiente e a recuperação mais rápida.

Outros trabalhos que também merecem atenção foram desenvolvidos por Yang (1996), James (1997), Mitchel (1999), Hall; Brody (2001) os quais evidenciaram em seus estudos que o alongamento gerava um aumento na produção de proteína contrátil e do número de sarcômeros, tanto em série como em paralelo. Estes novos sarcômeros são acrescentados ao final das miofibrilas existentes, resultando em um aumento no comprimento muscular (WILLIAMS; GOLDSPINK, 1971 ; WOLPAW; CARP, 1990). Barroso, Tricoli e Ugrinowitch (2005) ressaltam ainda que os sarcômeros em série favorecem a velocidade de contração enquanto os em PARALELO são determinantes para a força total do músculo. Por sua vez as proteínas contráteis são fundamentais para o processo de hipertrofia muscular (PEREIRA, SOUZA; MAZZUCO 2003).

Com base nos achados fisiológicos descritos acima, o alongamento tende a ser um meio de potencialização do treinamento força. Sendo assim o interesse sobre a interação do alongamento e do treinamento de força foi despertado gerando mais pesquisas sobre este assunto. Arruda et al. (2006) 
descreve em seu estudo que a flexibilidade e o treinamento de força são imprescindíveis para o aumento da eficiência do movimento uma vez que não se pode demonstrar o potencial de força se os músculos não possuírem uma $\mathrm{ADM}$ adequada, ou seja, a insuficiência da amplitude articular pode limitar o desenvolvimento de contrações voluntárias máximas aumentando o gasto energético e tornando assim o trabalho a ser realizado mais difícil.

Deste modo o alongamento acabou sendo introduzido a alguns métodos de treino, como o pliométrico. Fleck; Kraemer (1999) citam em seu estudo que a realização de um estiramento muscular, anteriormente ao início de uma sessão, aumentará a quantidade de força produzida, porém se realizada em excesso pode vir a diminuir o total de força produzida, ou seja, um alongamento pré-exercício aumenta o desempenho da contração concêntrica subseqüente (GUEDES NETO et al., 2004) porém se realizado em excesso pode vir a deformar os componentes plásticos musculares baixando assim a força empregada no movimento subseqüente pela diminuição da transmissão de mensagens motoras (ARRUDA et al., 2006).

Carvalho e Borges (2001) corroboram com esta idéia citando que uma musculatura tem potencializado o seu transporte de fluídos e a sua capacidade mecânica de realizar contrações ao apresentar um bom grau de alongamento (extensibilidade) permitindo assim uma melhor economia de energia.

Sendo o alongamento um provável encarregado pelo aumento no espaço sarcoplasmático, disponibilizando uma maior reserva de nutrientes, facilitando o transporte de fluídos, gerando um aumento na produção de proteína contrátil e do número de sarcômeros, beneficiando ainda uma amplitude articular favorável para a produção de força, ele possuiria influência direta no resultado do treinamento de força, neste caso através o desenvolvimento da secção transversa do músculo, ou seja, na hipertrofia muscular.

Com base nas adaptações fisiológicas que foram atribuídas ao alongamento descritas anteriormente ele poderia vir a ser um excelente potencializador do treinamento de força, logo, o objetivo desta pesquisa foi analisar os efeitos do alongamento durante o treinamento de força tendo como foco principal a hipertrofia muscular.

\section{METODOLOGIA}

O presente estudo se caracteriza pelo tipo experimental, estudo de caso, baseado em investigação. A 
amostra foi constituída basicamente por um indivíduo de 20 anos de idade, do sexo masculino, possuindo o lado direito do corpo dominante. O pesquisado, segundo anamnese aplicada, foi classificado, por meio de questionário IPAQ versão curta (MATSUDO et al., 2002), como sedentário, por não realizar nenhuma atividade física por pelo menos 10 minutos contínuos durante a semana. A participação no estudo foi de modo voluntário, onde os itens do questionário PARQ foram respondidos negativamente e um termo de consentimento de livre esclarecido foi assinado por parte do avaliado.

O programa de treinamento elaborado para a pesquisa teve duração de 8 semanas, onde o avaliado pode realizar 32 sessões de treino, sendo 16 destas de treinamento A (membros superiores) e 16 de treinamento B (membros inferiores). Sendo realizadas durante a semana em dias alternados com uma folga após uma seqüência de dois dias consecutivos (A - B - Folga - A - B).

As sessões de membros superiores consistiam na realização de dois exercícios de bíceps braquial (Rosca Direta e Scott) e dois de tríceps braquial (Tríceps Testa e Roldana Unilateral). Todos os exercícios da sessão A foram executados com halteres em três séries de oito repetições cada. As sessões de membros inferiores foram compostas dos exercícios Leg Press, Extensão de Joelho, Flexão de Joelho sentado e Flexão de Joelho em pé. Todos os exercícios da sessão B eram realizados de modo unilateral em três séries de oito repetições cada.

Antes de iniciar o programa de treinamento o individuo foi submetido a uma bateria de testes a qual foi repetida ao termino da $4^{\mathrm{a}}$ semana de treino e novamente ao final da $8^{\mathrm{a}}$ semana de treinamento. Esta bateria consistia em verificar o perímetro do braço direito e esquerdo, o perímetro das coxas direita e esquerda (porção medial), a espessura das pregas cutâneas bicipital, tricipital e crural direita e esquerda. Para tomada de tais medidas foi utilizado o protocolo padrão descrito por Hey ward (2000). Completando a bateria de testes foi realizado um teste de estimativa da carga máxima para cada exercício a ser realizado posteriormente no treinamento através da escala de Lombardi (LOMBARDI, 1989).

Pelo fato da amostra ter sido classificada como sedentária pelo questionário IPAQ foi adotado o seguinte processo metodológico com o objetivo de adaptar o sujeito em avaliação ao treinamento: Na primeira semana as cargas utilizadas foram de $50 \%$ da carga máxima obtida no teste com intervalos entre as séries de um minuto e meio. Na segunda e na terceira semana o \% da carga subiu para $70 \%$ mas o tempo de intervalo se manteve igual. Da terceira a oitava semana o percentual utilizado se manteve em $70 \%$ porém com intervalos de um minuto entre as séries. Entre um exercício e outro o tempo de 3

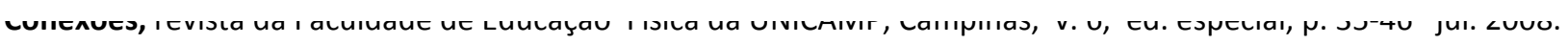
ISSN: $1983-9030$. 
minutos era concedido para recuperação do avaliado. O percentual de carga utilizado obtido através do teste de estimativa de carga máxima (LOMBARDI, 1989) realizado de modo unilateral, onde cada membro treinava com seu percentual correspondente.

Diariamente o avaliado desenvolvia seu treinamento da seguinte forma : Primeiramente um aquecimento específico prévio (Sessão A - rosca direta / Sessão B -leg press) com duas séries de 20 repetições em intensidade de $30 \%$ da carga máxima com intervalos de um minuto e meio, em seguida era realizado os alongamentos no membro esquerdo específico da sessão (Figura 1 e 2), para assim dar início ao processo metodológico descrito acima. Ao final de cada sessão o avaliado voltava a realizar os alongamentos específicos da sessão para o membro esquerdo.

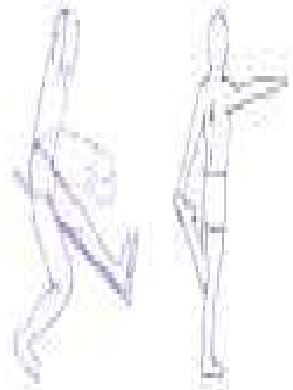

Biceps Femoral Quadríceps

Figura 1- Alongamentos de M.I.
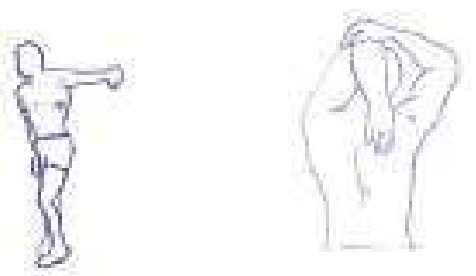

Bíceps Braquial Tríceps Braquial

Figura 2 - Alongamentos de M.S. 
Os alongamentos eram executados de modo ativo sendo específicos à sua sessão de treino (Figura 1 e 2), realizados em duas séries de 20 segundos em cada posição com intervalos de 30 segundos, sendo solicitado ao avaliado a execução de intensidade moderada (até o ponto de leve desconforto) no inicio da sessão e de intensidade moderada a alta (até o ponto de grande desconforto) ao final do treino, sempre nos membros sinistros.

\section{APRESENTAÇÃO E DISCUSSÃO DOS RESULTADOS}

A Tabela 1 apresenta os dados obtidos nas avaliações pré-treinamento, pós-4 ${ }^{\mathrm{a}}$ semana e pós-treinamento, os quais serão discutidos na seqüência.

Tabela 1 - Resultados das Avaliações

\begin{tabular}{lccc}
\hline \multicolumn{1}{c}{ Medida } & Pré* & Durante** & Pós*** \\
\hline Perímetro Braço Esquerdo & $24 \mathrm{~cm}$ & $24,5 \mathrm{~cm}$ & $25,5 \mathrm{~cm}$ \\
Perímetro Braço Direito & $24 \mathrm{~cm}$ & $25 \mathrm{~cm}$ & $26 \mathrm{~cm}$ \\
Perímetro Coxa Direita & $44,1 \mathrm{~cm}$ & $45,8 \mathrm{~cm}$ & $47,5 \mathrm{~cm}$ \\
Medial & & & \\
Dobra Bicipital Esquerda & $2,5 \mathrm{~mm}$ & $2,0 \mathrm{~mm}$ & $2,0 \mathrm{~mm}$ \\
Dobra Tricipital Direita & $5,5 \mathrm{~mm}$ & $4,6 \mathrm{~mm}$ & $4,6 \mathrm{~mm}$ \\
Dobra Tricipital Esquerda & $5,0 \mathrm{~mm}$ & $3,8 \mathrm{~mm}$ & $3,8 \mathrm{~mm}$ \\
Dobra Crural Direita & $10,3 \mathrm{~mm}$ & $8,5 \mathrm{~mm}$ & $7,9 \mathrm{~mm}$ \\
Dobra Crural Esquerda & $11,5 \mathrm{~mm}$ & $8,3 \mathrm{~mm}$ & $7,0 \mathrm{~mm}$ \\
\hline
\end{tabular}

\footnotetext{
*Avaliação realizada antes do programa de treinamento

** Avaliação realizada após a 4* semana de treinamento

*** Avaliação realizada ao término do programa de treinamento
}

Os Gráficos 1 e 2 apresentam o efeito das oito semanas de treinamento de força no desenvolvimento da circunferência dos M.S. (braços) e M.I. (coxas porção medial) respectivamente. Pode-se observar um melhor desempenho dos membros destros sobre os sinistros, dando força a idéia de que os alongamentos interferem negativamente no desenvolvimento de força, consequentemente em um trabalho de hipertrofia muscular. Esta hipótese vai de encontro aos achados de Arruda et al. (2006) o qual cita em seu estudo que o alongamento pode intervir negativamente na capacidade de desenvolvimento de força máxima devido à transmissão mais lenta das mensagens motoras causadas pelas deformações dos componentes plásticos musculares. Simão et al. (2003) agrega a esta linha de pensamento afirmando 
que há uma redução da ativação no recrutamento das unidades motoras.

Estes autores ainda concluem que um maior tempo de alongamento possibilita o relaxamento das fibras musculares ocasionando a redução do tônus muscular pela ativação do sistema paras simpático. Carvalho e Borges (2001) completam ainda afirmando que um tempo demasiado na execução do alongamento pode causar uma fadiga excessiva no músculo.

Sendo assim, o tempo de alongamento realizado neste estudo pode ter sido fundamental na resposta obtida na perimetria muscular, ou ainda a intensidade de realização do mesmo (duas séries de 20 segundos), pois o excesso de estiramento muscular antecedente ao treino poder vir a diminuir o total de força produzida durante o mesmo (G. NETO et al., 2005)

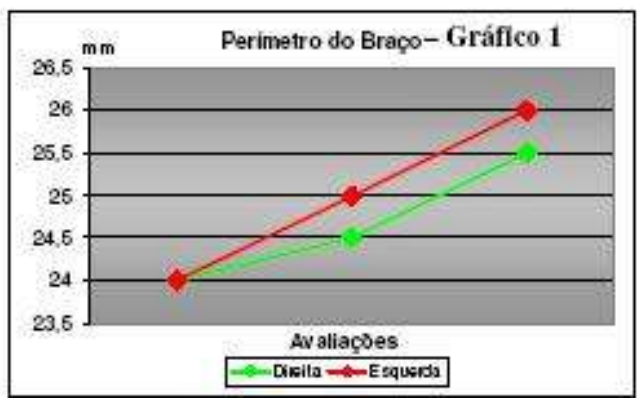

Embora existam boas evidências de que o tempo e a intensidade de execução do alongamento realizado neste estudo possam ter sido determinante no resultado menos expressivo dos membros alongados, é importante ressaltar que o avaliado possuía seu lado direito dominante, logo, utilizava-o com maior freqüência em suas atividades diárias, e esta maior utilização pode ter desencadeado uma solicitação maior de unidades motoras ao longo do tempo pré-treinamento, causando assim uma antecipação no processo de adaptação. Como os membros não alongados possuíam uma maior quantidade de unidades motoras recrutadas pré-treinamento, o tempo do processo de adaptação neural acabou sendo encurtado, passando com maior facilidade pelos processos de coordenação intramuscular e intermuscular, sincronismo de disparo, solicitando outras unidades motoras mais rapidamente até chegar ao processo de hipertrofia muscular antecipadamente (FLECK; KRAEMER, 1999). Os membros sinistros por sua vez tiveram este processo mais longo pela falta do uso diário. Ao analisarmos os gráficos 1 e 2 (circunferência nos M.S. e M.I.) chegamos a esta hipótese, pois é visível um crescimento linear dos membros destros enquanto os sinistros demoraram um pouco mais para acentuar seu crescimento, porém após um pequeno 
período de "adaptação" obtiveram um aproveitamento igual (M.S.) e até superiores (M.I.) aos dos membros não alongados.

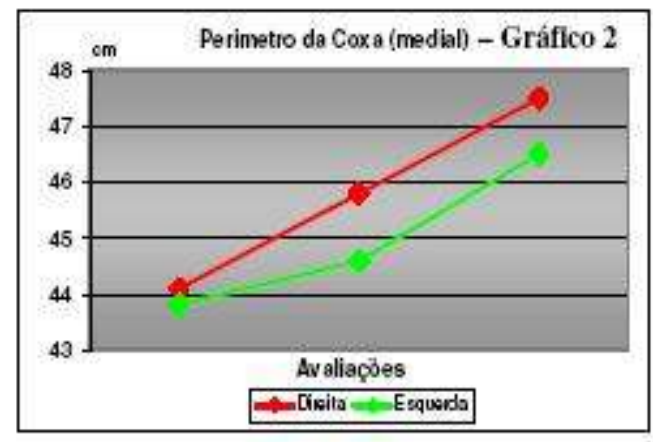

Os gráficos 3 e 4 apresentam o efeito das oito semanas de treinamento de força em relação à espessura de gordura subcutânea nos M.S. e M.I. respectivamente. Na tabela 3 podemos observar uma diminuição linear do tecido adiposo tanto no membro alongado quanto no não alongado, houve uma pequena ênfase na diminuição da espessura da prega tricipital alongada na fase inicial do treinamento, Pregas Cutâneas do Braço - Gráfico 3 porém esta foi "estabilizada" no decorrer do programa. Esta pequena ênfase citada anteriormente pode ser atribuída aos acontecimentos explícitos no gráfico 4 (Pregas Cutâneas dos M.I.), o qual nos permite observar uma diminuição acentuada na espessura da gordura subcutânea no membro alongado. Sendo os membros inferiores (Gráfico 4) suscetíveis a uma maior probabilidade de encurtamento muscular do que os superiores, este fato nos leva a hipótese de que além do alongamento ajudar no ganho de amplitude de movimento pode também ter influência numa possível redistribuição de gordura corporal, pois os resultados do Gráfico 4 (Pregas Cutâneas dos M.I.) demonstram um aproveitamento superior do membro alongado que era passível de maior encurtamento, no caso a posterior de coxa. A diminuição acentuada do tríceps na fase inicial do pro grama (Gráfico 3) também pode ser explicada por esta hipótese, sendo o tríceps esquerdo levemente encurtado pré-treinamento.

Contudo esta é apenas uma especulação, necessitando de mais estudos para verificação real da influência do alongamento e a redistribuição de gordura corpórea. Pereira, Souza e Mazzuca (2003) citam também observaram um aumento da massa corporal magra e a diminuição dos conteúdos de gordura subcutânea, após o trabalho com pesos. 

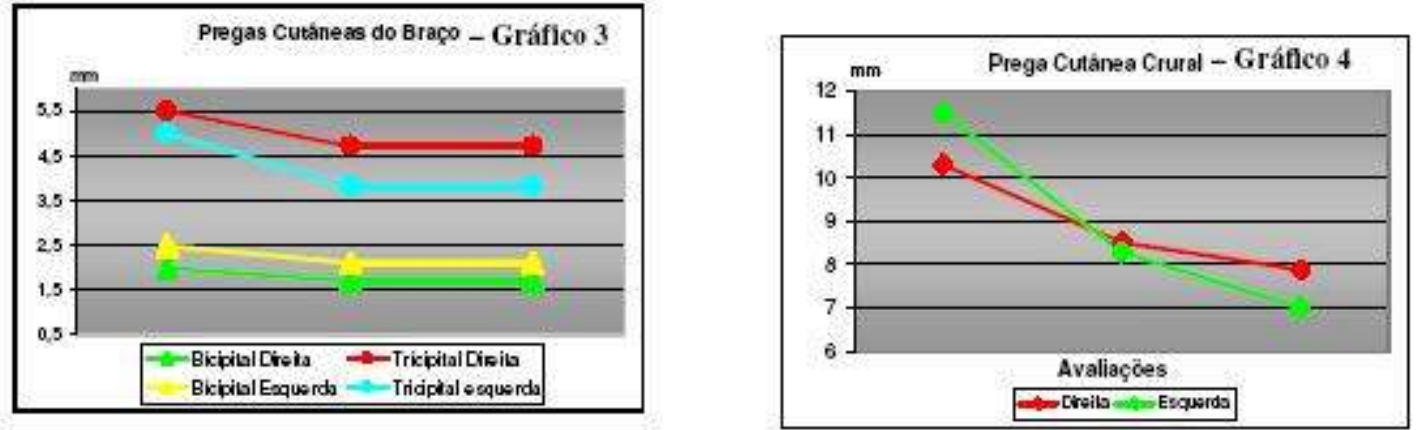

\section{CONSIDERAÇÕES FINAIS}

Com base nos resultados desta pesquisa o alongamento quando aliado ao treinamento de força não apresentou um melhor desempenho em relação à hipertrofia muscular, pelo contrário, os membros alongados tiveram um aproveitamento inferior ao do membro alongado, porém o autor atribui este fato ao sujeito pesquisado ter seu lado não-alongado dominante, facilitando o processo de adaptação ao treinamento obtendo assim uma hipertrofia muscular antecipadamente. Em relação às pregas cutâneas o treinamento de força contribuiu para a diminuição da sua espessura porém os membros alongados tiveram um aproveitamento superior, acredita-se que por uma possível redistribuição de gordura subcutânea, especialmente nos membros passiveis de maior encurtamento muscular, no caso a posterior de coxa e o tríceps braquial. Todavia são necessários mais estudos para obtenção de resultados mais expressivos nesta questão, com um tempo e uma amostragem maior para determinar os verdadeiros efeitos do alongamento no treinamento de força tendo como foco principal a hipertrofia muscular.

\section{REFERÊNCIAS}

ALTER, M. J. Alongamento para os esportes. 2. ed. São Paulo: Manole, 1999.

ARRUDA, F. L. B; et al. A influência do alongamento no rendimento do treinamento de força, Treinamento Desportivo, v. 7, n. 1, p. 01-05, 2006.

BARROSO, R.; TRICOLI, V.; UGRINOWITSCH, C. Adaptações neurais e morfológicas ao treinamento de força com ações excêntricas. Revista Brasileira de Ciência e Movimento. v. 2, n. 13, p. 111-122, 2005.

BROOKS, D. S. Treinamento personalizado: elaboração e montagens de programas. Guarulhos: Phorte, 2000.

Conexões, revista da Faculdade de Educação Física da UNICAMP, Campinas, v. 6, ed. especial, p. 35-46 jul. 2008. 
CARVALHO, J.; BORGES, G. Exercício de alongamento e as suas implicações no treinamento de força. Caderno de Educação Física, Estudos e Reflexões, v. 3, n. 2, p. 67-78, 2001.

FLECK, S; KRAEMER, W. Fundamentos do treinamento de força muscular. Porto Alegre: ArtMed, 1999.

GUEDES NETO. C. L. et al. Atuação do ciclo alongamento: encurtamento durante as ações musculares pliométricas. Journal of Exercise and Sport Sciences. v. 1, n. 1, jan./jul. 2005.

HALL, M. C; BRODY, T. L. Exercícios terapêuticos: na busca da função. Rio de Janeiro: Guanabara Koogan, 2001.

HÄUSSINGER, D. et al. Cell swelling inhibits proteolysis in perfused rat liver. Biochemical Journal, v. 272, n. 1, p. 239-142, 1990.

HEYWRD, V.; STOLARCZYK, L. Avaliação da composição corporal aplicada. São Paulo: Manole, 2000.

JAMES, R. S. et al. Mechanical properties of rabbit latissimus dorsi muscle after stretch and/or electrical stimulation. Journal of Applied Physiology, v. 83, n. 2, p. 398-406, 1997.

LOMBARDI, V. P. Beginning weight training: the safe and effective way; Dubuque, IA: W.C. Brown, 1989.

MATSUDO, S. M; et al. Nível de atividade física da população do estado de São Paulo: análise de acordo com o gênero, idade, nível socioeconômico, distribuição geográfica e de conhecimento. Revista Brasileira de Ciência e Movimento, v. 10, n. 4, p. 41-50, out. 2002.

MILLWARD, D. J. A. Protein-stat mechanism for regulation of growth and maintenance of the lean body mass. Nutrition Research Reviews. v. 8, p. 93-120, 1995.

MITCHELL, P; STEENSTRUP, T; HANNON, K. Expression of the fibroblast growth factor family during postnatal skeletal muscle hypertrophy. Journal of Applied. Physiology. v.86, n. 1, p. 313-319, 1999.

PEREIRA, J. L; SOUZA, E. F; MAZZUCO, M. A. Adaptações fisiológicas ao trabalho de musculação. Fiep Bulletin, v. 73, n. esp. p. 316-319, 2003.

SIMÃO, R. et al. A influência do aquecimento específico e da flexibilidade no teste de 1 RM. Revista Brasileira de Fisiologia do Exercício, v. 2, 2003.

YANG, $\mathrm{H}$ et al. Changes in muscle fibre type, muscle mass and IGF-I gene expression in rabbit skeletal muscle subjected to stretch. Journal of Anatomy, v. 190, n. 4, p. 613-622, 1997.

YANG, S et al. Cloning and characterizatio of an IGF-1 isoform expressed in skeletal muscle subjected 
to stretch. Journal of Muscle Research and Cell Motility, v. 17, n. 4, p. 487-495, 1996.

WILLIAMS, P. E; GOLDSPINK, G. Longitudinal growth of striated muscle fibres. Journal Cell Science, v. 9, n. 3, p. 751-767, 1971.

WOLPAW, J. R; CARP, J. S. Memory traces in spinal cord. Trends in Neurocience, v. 13, n. 4, p. 137$142,1990$. 


\section{Gustavo dos Santos Ribeiro}

\section{Curso de Pós-graduação em Fisiologia do Exercício - UFRGS}

\section{Referência do artigo:}

\section{ABNT}

RIBEIRO, G. S. (2008). O alongamento como fator interviniente na hipertrofia muscular: um estudo preliminar. Conexões, v. 6, (ed. especial), 35-46.

APA

Ribeiro, G. S. (2008). O alongamento como fator interviniente na hipertrofia muscular: um estudo preliminar. Conexões, v. 6, (ed. especial), 35-46.

\section{VANCOUVER}

Ribeiro, GS. O alongamento como fator interviniente na hipertrofia muscular: um estudo preliminar. Conexões, 2008; 6(ed. especial): 35-46. 